\title{
Assédio sexual no ambiente laboral: Um estudo com servidores públicos de uma universidade federal do Rio Grande do Sul
}

\author{
Sexual harassment in the workplace: A study with civil servants at a federal university of Rio
}

\author{
Grande do Sul
}

acoso sexual en el lugar de trabajo: Un estudio con servidores públicos de una universidad federal

de Rio Grande do Sul

Recebido: 01/04/2021 | Revisado: 10/04/2021 | Aceito: 13/04/2021 | Publicado: 26/04/2021

\author{
Gisela Sartori Farencena \\ ORCID: https://orcid.org/0000-0002-5927-3199 \\ Universidade Federal de Santa Maria, Brasil \\ E-mail: gisela.adm.95@gmail.com \\ Sheila Kocourek \\ ORCID: https://orcid.org/0000-0001-8962-8758 \\ Universidade Federal de Santa Maria, Brasil \\ E-mail: sheilakocourek@gmail.com \\ Vívian Flores Costa \\ ORCID: https://orcid.org/0000-0002-1822-7823 \\ Instituto Federal de Educação, Ciência e Tecologia Farroupilha, Brasil \\ E-mail: vivianfc13@gmail.com
}

\begin{abstract}
Resumo
O assédio sexual no ambiente de trabalho é uma realidade que atinge diversas organizações. Em muitas instituições, este tipo de violência ocorre especialmente quando há relações de poder e hierarquia envolvidas, e está diretamente ligada a questões culturais, como o machismo e o patriarcalismo, que acabam colaborando para casos de violência, muito em parte interligadas à discriminação de gênero. Este estudo tem por objetivo analisar a incidência de situações que configuram assédio sexual entre servidores de uma Universidade Federal do Interior do Rio Grande do Sul, a partir do Modelo de Avaliação de Experiências Sexuais proposto por Fitzgerald et al. (1999). Para isto, foi realizado um estudo de caso, de cunho quantitativo e caráter descritivo, cujo público-alvo compreende os servidores da instituição. A coleta de dados foi realizada com aplicação de questionário on-line, por meio do próprio sistema da Instituição, contando com a participação de 513 servidores. A análise de dados envolveu estatísticas descritivas, a partir do Sofware SPSS 20. Como resultados, percebeu-se que a maioria dos servidores nunca vivenciou as situações apresentadas no questionário. Apesar disso, há casos de assédio sexual ocorrendo tanto contra mulheres quanto contra homens servidores da instituição, mas as estatísticas evidenciaram que são elas as maiores vítimas dessa forma de violência.
\end{abstract}

Palavras-chave: Assédio sexual; Ambiente laboral; Universidade pública.

\begin{abstract}
Sexual harassment in the workplace is a reality that affects many organizations. In many institutions, this type of violence occurs especially when there are power relations and hierarchy involved, and is directly linked to cultural issues, such as sexism and patriarchy, which end up collaborating to cases of violence, very in part interconnected to gender discrimination. This study aims to analyze the incidence of situations that constitute sexual harassment among employees of a Federal University in the interior of Rio Grande do Sul, based on the Model for Evaluating Sexual Experiences proposed by Fitzgerald et al. (1999). For this, a case study of quantitative and descriptive nature was carried out, whose target audience includes the institution's employees. Data collection was carried out using an online questionnaire, through the institution's own system, with the participation of 513 employees. The data analysis involved descriptive statistics, using the SPSS 20 software. As a result, it was noticed that most of the employees had never experienced the situations presented in the questionnaire. Despite this, there are cases of sexual harassment occurring against both female and male employees of the institution, but the statistics showed that women are the biggest victims of this form of violence.
\end{abstract}

Keywords: Sexual harassment; Workplace; Public university.

\section{Resumen}

$\mathrm{El}$ acoso sexual en el trabajo es una realidad que afecta a muchas organizaciones. En muchas instituciones, este tipo de violencia se da sobre todo cuando intervienen relaciones de poder y jerarquía, y está directamente vinculada a 
cuestiones culturales, como el machismo y el patriarcado, que acaban colaborando en casos de violencia, muy en parte ligada a la discriminación de género. Este estudio tiene como objetivo analizar la incidencia de situaciones que constituyen acoso sexual entre empleados de una Universidad Federal del Interior de Rio Grande do Sul, con base en el Modelo de Evaluación de Experiencia Sexual propuesto por Fitzgerald et al. (1999). Para ello, se realizó un estudio de caso, de carácter cuantitativo y descriptivo, cuyo público objetivo son los empleados de la institución. La recolección de datos se realizó con la aplicación de un cuestionario online, a través del sistema propio de la institución, con la participación de 513 funcionarios. El análisis de datos involucró estadísticas descriptivas, basadas en el software SPSS 20. Como resultado, se notó que la mayoría de los servidores nunca experimentaron las situaciones presentadas en el cuestionario. A pesar de esto, existen casos de acoso sexual que ocurren tanto contra mujeres como contra hombres al servicio de la institución, pero las estadísticas han demostrado que son las mayores víctimas de esta forma de violência.

Palabras clave: Acoso sexual; Lugar de trabajo; Universidad pública.

\section{Introdução}

Dentre as muitas formas de violência que podem ser observadas diariamente no ambiente laboral, uma muito presente e ainda pouco debatida é o assédio sexual. Entretanto, as pesquisas ainda são escassas, especialmente quando se trata da temática do assédio sexual no ambiente de trabalho de instituições públicas, conforme demonstram Farencena, Kocourek, Silva e Dorion (2020), corroborando para a importância de aprofundar e expandir os estudos do tema, tão grave e presente na rotina de muitas mulheres.

Santos (2018) enfatiza que os indivíduos estão inseridos em um ambiente onde o assediador é tolerado, pois sua atitude é amenizada quando confundida com brincadeira de mau gosto ou até chamada de cantada infeliz. Desse modo, é importante observar definições que possam trazer esclarecimentos. Para que seja caracterizado o assédio sexual, é preciso o não consentimento da pessoa assediada e o objetivo, por parte de quem assedia, de obter vantagem ou favorecimento sexual (Senado Federal, 2011). Para Ribeiro (2018, p. 24), “o assédio sexual consiste na abordagem repetida de uma pessoa a outra, com a pretensão de obter favores sexuais, mediante imposição de vontade. Ofende a honra, a imagem, a dignidade e a intimidade da pessoa".

O assédio sexual é uma forma de violência que pode ocorrer em qualquer local, mas, quando sua ocorrência se dá no ambiente de trabalho, a situação se torna ainda pior, mais desgastante e humilhante, uma vez que é local onde a vítima e o assediador acabam convivendo diariamente. Tal forma de violência atinge em grande maioria mulheres, devido ao fato de este segmento ainda ocupar posições subalternizadas no mercado de trabalho, sendo, consequentemente, mais suscetíveis a investidas desta natureza por parte dos superiores (Diniz, 2014). Contudo, deve-se observar que nem toda relação no ambiente de trabalho constitui assédio sexual. É possível que existam relações com consentimento entre colegas de trabalho, o que não constitui crime algum.

Embora não haja um motivo específico para a ocorrência do assédio sexual no local de trabalho, algumas circunstâncias podem contribuir para a ocorrência de casos neste ambiente, como: existência de uma cultura organizacional que não pune os comportamentos intimidativos, relações insatisfatórias entre funcionários, exigências excessivas no trabalho, comportamentos discriminatórios e intolerância, problemas pessoais e consumo de drogas ou álcool (Ministério da Economia e Emprego, 2013). Destaca-se a relevância da primeira circunstância citada, uma vez que a falta de punição aos casos já ocorridos acaba por encorajar outros assediadores a praticar o assédio, sabendo que não sofrerão consequências. Mais um sério motivo para que as instituições levem a sério os casos e também abram espaço para as discussões da temática.

Nesse sentido, o objetivo desta pesquisa é analisar a incidência de situações que configuram assédio sexual entre servidores de uma Universidade Federal do Interior do Rio Grande do Sul, a partir do Modelo de Avaliação de Experiências Sexuais proposto por Fitzgerald, Drasgow, Magley e Waldo (1999). Como objetivo específico, busca-se analisar as diferenças nas experiências de assédio sexual de acordo com o sexo dos respondentes. 


\section{Fundamentação Teórica}

O papel da mulher na sociedade, desde os primórdios, foi muito delimitado. A ela, cabia cuidar dos seus filhos e do lar, enquanto os homens ocupavam-se de prover o sustento da família. Para Oliveira, Guimarães e Ferreira (2017), quando se questiona o papel da mulher, este está diretamente ligado ao patriarcalismo, sistema onde o sexo masculino é visto como superior ao feminino, "caracterizado por uma economia domesticamente organizada, na qual as mulheres tornam-se objeto de satisfação sexual dos homens, reprodutoras de herdeiros, de trabalho e de novas reprodutoras” (Osterne, 2012, p. 131).

Oliveira et al. (2017) ainda colocam que histórias infantis, mitos e costumes religiosos associam mulheres a seres pecadores, passivos e dependentes do homem para proteção, legitimando o sistema patriarcal, estando essa imagem inclusive presente nas mídias atualmente, onde se mostra o corpo feminino como objeto. Não se pode deixar de citar também o estereótipo formado sobre o homem "macho" que é visto como "indivíduo corajoso, viril, esperto, forte e imune às fragilidades" (Osterne, 2012, p. 130), o que parece que lhes dá o direito de agir de modo agressivo contra as mulheres, especialmente porque estas, ainda de acordo com a mesma autora, têm o estereótipo baseado na "fraqueza, fragilidade, nãovalorização de sua capacidade”.

Muito já foi feito, mas ainda muito precisa ser conquistado para superar as diferenças entre homens e mulheres. Nesse contexto, mulheres lutaram e seguem lutando por direitos iguais. Nesse sentido, surgiu, a partir da década de 60, o movimento feminista ${ }^{1}$, buscando questões que são discutidas até hoje, como: o fim da diferença salarial entre homens e mulheres, o fim da violência e do assédio, uma maior participação na política e o domínio do próprio corpo, buscando direito de decisão sobre questões como o aborto, entre outros (Fahs, 2016).

Apesar da busca por direitos iguais, as desigualdades são muitas, inclusive no mercado de trabalho. Como já mencionado, há poucos anos as mulheres tinham como exclusiva função cuidar do lar, mas, aos poucos, foram adentrando no mercado de trabalho nas mais diferentes atividades. Todavia, ainda hoje existe preconceito e se define alguns ofícios como "trabalho de homem" e "trabalho de mulher". Esse problema ainda existe no mundo inteiro, e atinge mulheres dos mais diferentes credos, raça, etnia, religião ou qualquer condição.

Somado a isso, ainda se percebe a existência de discriminação salarial entre as partes, o que acaba gerando cada vez mais curiosidade dos pesquisadores. Na Pesquisa Nacional por Amostra de Domicílios Contínua (PNAD), realizada em 2018 pelo Instituto Brasileiro de Geografia e Estatística (IBGE), e compreendendo o período de 2012 a 2018, é possível observar essa disparidade. As mulheres brasileiras receberam, em média, em 2012, 89,1\% da remuneração dos homens, e no ano de 2018, 91,5\%, em relação à hora trabalhada. O rendimento médio total aparece bastante inferior para as mulheres, sendo que, em 2012, elas recebiam 76,6\% do salário masculino, e em 2018, estas ainda recebem remuneração que corresponde somente a 79,5\% do valor que os homens recebem (Instituto Brasileiro de Geografia e Estatística [IBGE], 2018).

A mesma situação é válida no que se refere à ocupação de cargos de gestão, os quais são ocupados, em maioria, pelos homens. Dados da própria Universidade pesquisada mostram que essa disparidade também existe na instituição, ainda que não seja uma diferença tão expressiva. Dos 944 cargos de gestão da instituição, 86 estavam vagos no momento da consulta, 474 ocupados por homens e 384 por mulheres ${ }^{2}$, sendo uma disparidade relevante.

Todos esses indicativos podem estar relacionados ao assédio de gênero. Para Osterne (2012, p. 133), “a violência contra a mulher é um dos principais indicadores da discriminação de gênero em suas diferentes formas de expressão, variando do assédio moral e da violência psicológica até as manifestações extremas de agressão física e sexual". Nesse sentido, o assédio sexual enquanto forma de violência contra a mulher deve ser discutido.

\footnotetext{
${ }^{1} \mathrm{O}$ feminismo é um movimento que busca igualdade de direitos e oportunidades das mulheres perante os homens.

${ }^{2}$ Dados gerados e fornecidos via e-mail, em 13 de março de 2020, pelo Núcleo de Acompanhamento de Cargos e Funções, da Pró-Reitoria de Gestão de Pessoas da UFSM.
} 
Historicamente, mulheres e homens sempre foram ensinados e cobrados de maneira diferente. Enquanto as meninas deviam se comportar e sentar de pernas fechadas, os meninos tinham muito mais liberdades, deixando subentendido uma inferioridade feminina (Sá, Folriani e Rampazo, 2017). Diante disso, pode-se dizer que o homem sentiu que possuía, além de superioridade, o direito de diminuir ainda mais o sexo feminino e ter poder sobre este. Neste cenário, as diferentes formas de violência contra as mulheres ocorrem, e não de modo isolado. Isso contribui para a ocorrência dos diferentes tipos de violência contra a mulher, sendo um deles o assédio sexual, que "pode ocorrer tanto numa relação de poder institucionalizada e formalizada, quanto em outras relações que não envolvam necessariamente hierarquia explícita, mas que recorram a uma hierarquização de gênero socialmente construída" (Teixeira e Rampazo, 2017, p. 1160).

Deve-se evitar a confusão entre assédio sexual e cantadas e elogios. Assediar é o ato de "perseguir de maneira insistente, geralmente com propostas" e/ou "insistir de modo ofensivo, com a intenção de seduzir alguém ou manter relacionamento sexual, servindo-se geralmente do poder que detém". Cantada é "a conversa hábil e cativante com que se tenta seduzir ou conquistar alguém", e elogio é "um parecer favorável que se dá em favor de alguém"”. Logo, percebe-se que a característica do assédio sexual que o diferencia de cantadas e elogios está na insistência, uso do poder e ofensas.

Quando se fala em assédio sexual no ambiente laboral, a sua ocorrência se dá, em grande parte, por questões de hierarquia explícita, que acaba dando ao homem a sensação de poder sobre a mulher, sentindo que possui o direito de fazer o que bem entender. Embora não haja um motivo específico para a ocorrência do assédio sexual no local de trabalho, algumas circunstâncias podem contribuir para a ocorrência de casos neste ambiente, como: existência de uma cultura organizacional que não pune os comportamentos intimidativos, relações insatisfatórias entre funcionários, exigências excessivas no trabalho, comportamentos discriminatórios e intolerância, problemas pessoais e consumo de drogas ou álcool (Ministério da Economia e do Emprego, 2013, p. 10). Destaca-se a relevância da primeira circunstância citada, uma vez que a falta de punição aos casos já ocorridos acaba por encorajar outros assediadores a praticar o assédio, sabendo que não sofrerão consequências. Mais um sério motivo para que as instituições enfrentem com seriedade casos.

Conforme exposto na Cartilha de Assédio Moral e Sexual no Trabalho, o assédio sexual no local de trabalho pode acontecer de duas formas: vertical ou horizontal. O assédio vertical ocorre quando um homem ou mulher, em posição hierárquica superior, se vale da sua posição de chefe para obter favorecimento sexual. Essa forma de assédio é caracterizada como crime e aparece no Código Penal. Já o assédio horizontal ocorre sem distinção hierárquica entre as partes, entre colegas de mesmo nível de trabalho. Esta forma ainda não está prevista no Código Penal, embora também seja passível de punição (Senado Federal, 2017).

Ainda, outra segmentação determina que o assédio sexual no ambiente laboral pode ser: assédio por chantagem e assédio por intimidação. $\mathrm{O}$ assédio por chantagem, também chamado quid pro quo, "ocorre quando há a exigência de uma conduta sexual, em troca benefícios ou para evitar prejuízos na relação de trabalho", enquanto o assédio por intimidação ocorre

[...] quando há provocações sexuais inoportunas no ambiente de trabalho, com o efeito de prejudicar a atuação de uma pessoa ou de criar uma situação ofensiva, de intimidação ou humilhação. Caracteriza-se pela insistência, impertinência, hostilidade praticada individualmente ou em grupo, manifestando relações de poder ou de força não necessariamente de hierarquia (Ministério Público do Trabalho [MPT], 2017, p. 10).

A prática de assédio sexual no ambiente laboral gera consequências para o assediador. Com o intuito de fazer cessar o assédio, o responsável pela instituição pode trabalhar por algumas mudanças em relação ao assediador, como a troca de setor de trabalho, a transferência para outra função, e até mesmo a dispensa por justa causa. Além das consequências trabalhistas,

\footnotetext{
${ }^{3}$ Dicionário Michaelis Online. Editora Melhoramentos. Disponível em: http://michaelis.uol.com.br/moderno-portugues/. Acesso em: 30 abr. 2020.
} 
também existem as punições penais e civis, e o assediador pode ser réu em ação civil pública proposta pelo Ministério Público do Trabalho ou Sindicato. Ademais, a vítima também pode buscar alterações em seu contrato, por meio de ação trabalhista, e até mesmo a rescisão do contrato de trabalho, sendo justa causa do empregador (MPT, 2017).

Quando se trata de assédio sexual no serviço público, na esfera estadual, alguns Estados têm legislação específica. Já nos órgãos públicos federais, embora a prática de assédio sexual não esteja claramente explicitada na Lei n ${ }^{\circ}$ 8.112/1990 (Regime Jurídico dos Servidores Civis da União), pode ter consequências no âmbito administrativo, gerando abertura de processo administrativo, a ser julgado por Comissão especializada, "pois afronta o dever de moralidade, podendo constituir-se em incontinência de conduta" (Conselho Nacional do Ministério Público [CNMP], 2016, p. 20). A depender do julgamento, o assediador pode sofrer até penalidade de demissão. O assédio sexual também pode configurar ato de improbidade administrativa, com base na Lei n. 8.429/1992, por atentar contra os princípios da Administração Pública, podendo levar à perda da função pública do agente (MPT, 2017).

\section{Metodologia}

A presente pesquisa é caracterizada, quanto à sua abordagem, como quantitativa. Para Fonseca (2002, p. 20), “a pesquisa quantitativa se centra na objetividade. Influenciada pelo positivismo, considera que a realidade só pode ser compreendida com base na análise de dados brutos, recolhidos com o auxílio de instrumentos padronizados e neutros". Quanto aos objetivos, trata-se de uma pesquisa descritiva, pois busca descrever características de determinada população ou fenômeno. Um de seus atributos é o uso de técnicas padronizadas de coleta de dados (Gil, 2008). Quanto à natureza, é uma pesquisa aplicada, uma vez que tem como característica o interesse na utilização dos conhecimentos para aplicação prática em uma realidade (Gil, 2008).

Caracteriza-se, também, como uma pesquisa de campo com survey. Nesse tipo de pesquisa, são solicitadas informações a um grupo de pessoas, acerca de um problema estudado para, posteriormente, a partir de análise quantitativa, poder elaborar uma conclusão a partir dos dados coletados (Gil, 2018).

O local escolhido para aplicação da pesquisa foi uma Universidade Federal do Interior do Rio Grande do Sul, que, atualmente, conta com cerca de 4,7 mil servidores, entre docentes e técnico-administrativos em educação, e mais de 26 mil alunos regularmente matriculados. A instituição foi escolhida para aplicação da pesquisa de modo intencional por ser local de trabalho das autoras. Além disso, por ser uma instituição de grande representatividade dentre as Universidades Federais gaúchas, com grande número de servidores e alunos, além de importância determinante no desenvolvimento econômico local e regional. Somado a isto, houve relevante número de denúncias de assédio sexual contra servidores da instituição nos últimos anos (Universidade Federal de Santa Maria [UFSM], 2019). Esse fato torna a população de servidores atrativa para a aplicação da pesquisa.

Para atingir os objetivos da pesquisa, foi escolhido como instrumento de coleta de dados um questionário. No que se refere aos respondentes da pesquisa, este estudo considerou todos servidores (as) ativos (as) da Universidade em questão, englobando tanto docentes quanto técnicos-administrativos em educação (TAE), de todos os campi da instituição. A população é composta por 4.751 servidores, sendo 2.070 da categoria docente e 2.681 da categoria TAE.

Desta população, foi extraída uma amostra, "por meio do qual se estabelecem ou se estimam as características do universo ou população" (Gil, 2008, p. 90). A amostra foi definida como probabilística, do tipo aleatória simples. Segundo Vergara (2016), ela é probabilística porque é baseada em procedimentos estatísticos, e é aleatória simples porque se refere aos casos em que cada elemento da população tem a mesma chance de ser selecionado. Para o cálculo da amostra, de modo que o estudo obtenha resultados confiáveis, foram considerados uma margem de erro de 5\% e confiabilidade $95 \%$. O cálculo 
amostral diante da totalidade da população estabeleceu a necessidade de 356 questionários válidos para explicar o fenômeno de modo confiável.

O questionário escolhido é uma versão traduzida para o português do Sexual Experiences Questionnaire (SEQ), representando o Modelo de Avaliação de Experiências Sexuais de Fitzgerald et al. (1999). A primeira versão do Questionário foi desenvolvida pelos autores em 1988, sendo um modelo de avaliação da ocorrência do assédio sexual através de cinco dimensões: assédio de gênero, comportamento sedutor, suborno sexual, coerção sexual e imposição sexual (Fitzgerald, Gelfand e Drasgow, 1995).

Mais tarde, após alguns estudos de diferentes pesquisadores apontarem críticas ao modelo, Fitzgerald, Gelfand, Drasgow (1995) decidiram realizar uma revisão do modelo proposto, com uma nova forma para as dimensões avaliadoras das experiências sexuais, desta vez resumidas a três, relacionadas mas conceitualmente distintas. Na revisão realizada, os pesquisadores focaram em manter um instrumento curto, plenamente aplicável a organizações. Assim, foram mantidas três dimensões de assédio sexual, compostas por um total de 20 itens. As dimensões eram: assédio de gênero, atenção sexual indesejada e coerção sexual.

Em 1999, Fitzgerald et al. propuseram novas mudanças e revisão ao Questionário de Experiências Sexuais (SEQ), após observarem algumas limitações no modelo anterior, e para que o modelo pudesse ser aplicado a uma população militar (Forças Armadas). Assim, o SEQ precisou sofrer algumas adaptações para se encaixar a essa realidade. Para avaliar o efeito das revisões, submeteram o instrumento a um extenso exame de suas propriedades psicométricas e estruturais. Nessa análise, a estrutura previamente identificada foi replicada com uma exceção importante: em vez da solução de três fatores (três dimensões), análises fatoriais confirmatórias resultaram em uma solução de quatro fatores, que separou a dimensão "Assédio de Gênero" em duas categorias distintas: hostilidade sexista e hostilidade sexual. As estatísticas indicaram que a solução de quatro fatores caracterizou com precisão o conjunto de 23 itens que compunham o questionário (Fitzgerald et al., 1999). Assim, o novo modelo do SEQ, denominado pelos autores de SEQ-DoD, seria composto por quatro dimensões: hostilidade sexista, hostilidade sexual, atenção sexual indesejada e coerção sexual (detalhadas no Quadro 1), e 23 itens (apresentados no Quadro 2).

Quadro 1 - Dimensões que compõem o Questionário de Experiências Sexuais (SEQ).

\begin{tabular}{|c|c|}
\hline DIMENSÃO & CARACTERÍSTICAS \\
\hline Hostilidade Sexista & Assédio de gênero (experiências consideradas discriminatórias com base no sexo). \\
\hline Hostilidade Sexual & $\begin{array}{c}\text { Assédio de gênero através de experiências, mais explícitas de hostilidade, insultos } \\
\text { e humilhações com caráter sexual. }\end{array}$ \\
\hline Atenção Sexual Indesejada & $\begin{array}{c}\text { Comportamentos sexuais (verbais ou não-verbais) indesejados, como toques, } \\
\text { abraços ou repetidas solicitações ou pressões por encontros, agressões sexuais. }\end{array}$ \\
\hline Coerção Sexual & $\begin{array}{c}\text { Demandas implícitas ou explícitas por favores sexuais, através de ameaças de } \\
\text { consequências negativas ou promessas de recompensas relacionadas ao trabalho. }\end{array}$ \\
\hline
\end{tabular}

Fonte: Adaptado de Fitzgerald; Gelfand; Drasgow (1995, p. 430); Schneider; Swan (1997, p. 404-405); Fitzgerald et al. (1999, p. 249).

Além da pesquisa básica, o SEQ parece promissor como medida avaliação das necessidades institucionais, como indicado por sua capacidade de discriminar entre os padrões de assédio sofridos por mulheres em diferentes instituições e de diferentes níveis educacionais (Fitzgerald et al., 1988, p. 169), além de ser de fácil aplicação, por ser um instrumento curto e de prático uso nas organizações. Assim, o modelo é adequado para a realidade de uma instituição pública de ensino. Desse modo, foi utilizado, para aplicação da pesquisa, o instrumento SEQ em sua versão após revisão de 1999, traduzido para o idioma português, por uma profissional, e com pequenas adaptações, de modo a trazer maior clareza aos respondentes, resultando na versão final apresentada no Quadro 2. 
Quadro 2 - Questionário de experiências sexuais traduzido e adaptado.

\section{Questionário de Experiências Sexuais}

a. Repetidamente contou histórias sexuais ou piadas que foram ofensivas para você?

b. Assoviou, ligou ou ficou chamando você de uma maneira sexual?

c. Fez tentativas indesejadas de levá-la a uma discussão sobre questões sexuais (por exemplo, tentou discutir ou comentar sua vida sexual)?

d. Fez comentários sexuais grosseiros e ofensivos, tanto publicamente (por exemplo, no seu local de trabalho) ou para você em particular?

e. Tratou você de forma diferente por causa do seu sexo (por exemplo, maltratou, menosprezou ou ignorou)?

f. Fez comentários ofensivos sobre sua aparência, corpo ou suas atividades sexuais*?

*Foi adicionada uma observação ao final da frase: “(Obs.: ofensivos no sentido de menosprezar)”.

g. Fez gestos ou usou linguagem corporal de natureza sexual que a envergonhou ou ofendeu?

h. Exibiu, usou ou distribuiu materiais sexistas ou sugestivos (por exemplo, fotos, histórias ou pornografia que você considerou ofensivas)?

i. Fez comentários sexistas ofensivos (por exemplo, sugerindo que as pessoas do seu sexo não são adequadas para o tipo de trabalho que você faz)?

j. Fez tentativas indesejadas para estabelecer um relacionamento sexual romântico com você, apesar de seus esforços para desencorajá-lo?

k. Te deprimiu ou foi condescendente com você por causa do seu sexo?

1. Olhou-a, zombou uma maneira que fez você se sentir desconfortável?

m. Expôs-se fisicamente* de uma maneira que a envergonhou ou fez com que se sentisse desconfortável?

*Foi retirado: (por exemplo, "mostrou as nádegas" para você).

n. Continuou a convidar para encontros, bebidas, jantares, etc., mesmo que você tenha dito "Não"?

o. Você sentiu que estava sendo subornado com algum tipo de recompensa ou tratamento especial para se envolver sexualmente*?

*Substituiu-se "para se envolver em comportamento sexual" por "para se envolver sexualmente.

p. Você se sentiu ameaçada com algum tipo de retaliação por não ser sexualmente cooperativa (por exemplo, ao mencionar uma próxima tentativa)?

q. Tocou você de uma maneira que fez você se sentir desconfortável?

r. Fez tentativas indesejadas de afagar, acariciar ou beijar você?

s. Te tratou mal por se recusar a fazer sexo?

t. Sugeriu* promoções mais rápidas ou melhor tratamento se você fosse sexualmente cooperativa?

*Substituiu-se "implicou" por "sugeriu".

u. Fez você temer ser maltratada se não cooperasse sexualmente?

v. Tentou fazer sexo com você sem o seu consentimento ou contra a sua vontade, mas não teve sucesso?

x. Fez sexo com você sem seu consentimento ou contra sua vontade?

Fonte: Adaptado de Fitzgerald et al. (1999).

No momento da coleta de dados, apresentou-se aos respondentes o Termo de Consentimento Livre Esclarecido, que garante à pessoa que está respondendo o sigilo e respeito aos seus direitos. Após essa etapa, foram disponibilizadas as questões baseadas no Sexual Experiences Questionnaire (Questionário de Experiências Sexuais), que integram quatro dimensões 
investigadas (hostilidade sexista, hostilidade sexual, atenção sexual indesejada e coerção sexual), já mencionadas anteriormente. Os respondentes escolheram a melhor resposta de acordo com uma escala Likert de cinco pontos, relacionada à frequência de ocorrência das situações mencionadas, sendo (1) nunca, (2) uma vez, (3) mais de uma vez, (4) várias vezes e (5) sempre. Por fim, foram solicitados dados referentes ao perfil do respondente, como: idade, gênero, autodeclaração de raça, escolaridade, categoria, tempo de atuação na instituição e ocupação (ou não) de cargo de chefia.

Destaca-se que, antes de iniciar a coleta efetiva de dados, foi realizado um pré-teste, procedimento necessário, de acordo com Fonseca (2002), para que eventuais erros na formulação das questões possam ser corrigidos antes que a coleta oficial se inicie. Para esta pesquisa, o pré-teste contou com a participação de 11 respondentes, e somente um deles teve dúvida em uma questão, a qual sofreu um pequeno ajuste para evitar dúvidas e problemas futuros.

Os dados quantitativos foram coletados através do Sistema de Questionários disponibilizado aos servidores da Universidade, de forma on-line, no próprio site da instituição. Para isso, foi solicitado apoio do Centro de Processamento de Dados (CPD) da instituição, responsável por disponibilizar o questionário a todos os servidores, bem como solicitar a colaboração de resposta a todos por e-mail. A coleta ocorreu nos meses de abril e maio de 2020 e obteve-se participação de 513 respondentes.

Após alcançado (e ultrapassado) o número de questionários determinado pelo cálculo da amostra, o banco de dados obtido com as respostas, já tabuladas, foi disponibilizado pelo Centro de Processamento de Dados, e procedeu-se à análise. Esta foi feita com o auxílio dos softwares Windows Excel 2013 e Statistical Package for Social Science (SPSS) - versão 20. Através destes programas, foram realizados testes de estatísticas descritivas, descrevendo o perfil dos respondentes, a média e desvio-padrão das variáveis do questionário e também a análise fatorial exploratória a partir das mesmas. Para avaliar a confiabilidade dos fatores obtidos a partir da análise fatorial, foi empregado o indicador Alpha de Cronbach. Além disso, foi realizado "Teste T de amostras independentes", buscando apresentar o cálculo da média e desvio-padrão para cada variável componente do questionário a partir do sexo dos respondentes (feminino e masculino). Isso foi feito de modo a identificar se, na instituição pesquisada, mulheres apresentam maiores médias, ou seja, se são as maiores vítimas de assédio sexual.

No que se refere a aspectos éticos, o estudo está vinculado ao projeto "Assédio sexual no ambiente de trabalho de uma instituição federal de ensino superior: um estudo de caso", já aprovado pelo Comitê de Ética em Pesquisa com Seres Humanos da Universidade, em julho de 2018. Foi necessário realizar emenda ao projeto, etapa executada em fevereiro de 2020.

\section{Resultados e Discussão}

Neste capítulo, são abordados os principais resultados obtidos com a pesquisa. Primeiramente, são expostos resultados de estatísticas descritivas, para demonstrar as características gerais dos respondentes (perfil). Para melhor expor os resultados sobre o perfil, foram elaboradas as Tabelas 1 (perfil pessoal) e 2 (perfil profissional).

\subsection{Perfil dos Pesquisados}

A Tabela 1 apresenta informações do perfil pessoal dos respondentes da pesquisa, como sexo, idade, raça declarada e escolaridade. 
Tabela 1 - Perfil dos respondentes segundo as variáveis: sexo, idade, raça declarada e escolaridade.

\begin{tabular}{|c|c|c|c|}
\hline Variáveis & Alternativas & Frequência & Percentual \\
\hline \multirow{3}{*}{ Sexo } & Masculino & 223 & $43,5 \%$ \\
\hline & Feminino & 287 & $55,9 \%$ \\
\hline & Prefiro não responder & 3 & $0,6 \%$ \\
\hline \multirow{4}{*}{ Idade* } & De 23 a 35 anos & 140 & $27,3 \%$ \\
\hline & De 36 a 43 anos & 128 & $25 \%$ \\
\hline & De 44 a 53 anos & 119 & $23,2 \%$ \\
\hline & De 54 a 72 anos & 126 & $24,6 \%$ \\
\hline \multirow{6}{*}{ Raça declarada } & Amarelo (a) & 2 & $0,4 \%$ \\
\hline & Branco (a) & 460 & $89,7 \%$ \\
\hline & Indígena & 1 & $0,2 \%$ \\
\hline & Negro (a) & 7 & $1,4 \%$ \\
\hline & Pardo (a) & 31 & $6 \%$ \\
\hline & Prefiro não responder & 12 & $2,3 \%$ \\
\hline \multirow{6}{*}{ Escolaridade } & Ens. Médio Completo ou Técnico & 6 & $1,2 \%$ \\
\hline & Aperfeiçoamento & 1 & $0,2 \%$ \\
\hline & Superior Completo ou habilitação equivalente & 51 & $9,9 \%$ \\
\hline & Especialização & 85 & $16,6 \%$ \\
\hline & Mestrado & 126 & $24,6 \%$ \\
\hline & Doutorado & 244 & $47,6 \%$ \\
\hline
\end{tabular}

*A variável idade foi recodificada e dividida em quatro classes, a partir dos quartis identificados. Fonte: Dados da pesquisa (2020).

A participação de respondentes do público do sexo feminino (287 respondentes, 55,9\% do total) foi ligeiramente maior do que do sexo masculino (223 respondentes, 43,5\% do total), sendo que a ampla participação de servidores do sexo masculino surpreendeu positivamente. No que se refere à idade dos servidores que participaram da pesquisa, o maior percentual pertence à categoria de 23 a 35 anos, sendo 27,3\% do total e, de modo geral, mais da metade dos respondentes têm até 43 anos. Quanto à raça autodeclarada pelos respondentes, a grande maioria $(89,7 \%)$ se considera branco (a), seguidos de $6 \%$ que se consideram pardos.

Quanto à escolaridade/titulação dos respondentes, a maioria possui Doutorado, representando 47,6\% do total (N=244), seguidos de 24,6\% ( $\mathrm{N=126)}$ que têm Mestrado. Isso significa que mais de $70 \%$ dos participantes tem mais altos graus de formação. Tal dado pode ser explicado uma vez que a pesquisa contou com boa participação de servidores da categoria docente que, de modo geral, precisam ter titulação de Doutor (a) para poderem exercer o ensino em Instituições Federais. Além disso, servidores técnico-administrativos em educação também vêm buscando maiores níveis de especialização, ainda que o cargo não exija, devido ao plano de carreira que lhes permite ter melhorias salariais a partir dos estudos (Progressão por Capacitação e Incentivo à Qualificação), conforme o disposto na Lei N 11.091, de 12 de janeiro de 2005.

A Tabela 2 apresenta informações profissionais dos servidores da instituição, detalhando tempo de atuação na Instituição pesquisada, categoria de atuação (docente ou técnico-administrativo em educação) e se ocupam cargo de chefia no momento. 
Tabela 2 - Perfil dos respondentes segundo as variáveis: tempo de atuação na Universidade, categoria e ocupação de cargo de chefia.

\begin{tabular}{cccc}
\hline Variáveis & Alternativas & Frequência & Percentual \\
\hline \multirow{2}{*}{$\begin{array}{c}\text { Tempo de atuação na } \\
\text { Universidade* }\end{array}$} & Até 4 anos & 143 & $27,9 \%$ \\
\cline { 2 - 3 } & De 5 a 10 anos & 140 & $27,3 \%$ \\
\cline { 2 - 3 } & De 11 a 20 anos & 103 & $20,1 \%$ \\
\hline \multirow{2}{*}{ Categoria de atuação } & De 21 a 42 anos & 127 & $24,8 \%$ \\
\hline \multirow{2}{*}{ Ocupa cargo de chefia } & Docente & 255 & $49,7 \%$ \\
& TAE & 258 & $50,3 \%$ \\
\hline & Sim & 139 & $27,1 \%$ \\
\hline
\end{tabular}

*A variável tempo de atuação foi recodificada e dividida em quatro classes, a partir dos quartis identificados. Fonte: Dados da pesquisa (2020).

Quanto ao tempo de atuação dos servidores na Instituição pesquisada, a grande maioria são servidores "novos", uma vez que mais da metade do total atua na instituição no máximo há 10 anos: 27,9\% têm até 4 anos de atuação, e $27,3 \%$ têm de 5 a 10 anos. No que se refere à categoria de atuação dos servidores, a Universidade conta com servidores docentes e servidores técnico-administrativos em educação (TAE’s). A participação de ambas foi muito similar, visto que 50,3\% (N=258) dos respondentes foram TAE's, enquanto 49,7\% ( $\mathrm{N}=255)$ foram docentes. Dos 513 respondentes, quase $73 \%$ (374 pessoas) não ocupavam nenhum cargo de chefia no momento da pesquisa.

\subsection{Experiências de Assédio Sexual no Ambiente de Trabalho}

A fim de identificar as experiências de assédio sexual vivenciadas no local de trabalho dos servidores entrevistados, realizou-se a análise fatorial exploratória das variáveis que compõem o Questionário de Experiências Sexuais (SEQ) de Fitzgerald et al. (1999). Desse modo, a partir do total de 513 respostas válidas obtidas, foram utilizadas as 23 questões que compõem o instrumento para identificar de que modo são agrupadas em fatores, e se seguem a distribuição de fatores do modelo original. Os dados foram analisados com auxílio do software SPSS 20.

Para verificar se análise fatorial é adequada para o conjunto de dados, foram realizados dois testes: Kaiser-MeyerOlkin (KMO), que testa a consistência geral dos dados, e Teste de Esfericidade de Bartlett, que é o "teste estatístico da significância geral de todas as correlações em uma matriz de correlação” (Hair et al., 2009, p. 102). A análise inicial mostra que os testes KMO e Bartlett indicaram a fatorabilidade dos dados, uma vez que KMO=0,909 (superior a 0,7) e o Teste de Bartlett apresentou resultado significativo (SIG 0,000). Sendo assim, os dados podem ser utilizados.

Posteriormente, foi avaliada a comunalidade de cada uma das 23 questões do questionário. Observou-se uma (1) variável com comunalidade inferior a 0,5 , de modo que foi excluída. A questão excluída foi a "M", referente a exposição física: "Presenciou exposição física que gerou desconforto", com comunalidade 0,469 . Com a exclusão, o instrumento passou a ter 22 questões apropriadas para análise. Para avaliar a fatorabilidade dos dados após a exclusão da variável, foi realizada nova análise dos testes de KMO e Bartlett. O teste KMO apresentou valor igual a 0,911 e Bartlett teve resultado significativo (SIG 0,000). Logo, concluiu-se novamente pela fatorabilidade dos dados, dando sequência à determinação dos fatores.

Para determinar o número de fatores que explicam as variáveis, foram utilizados dois critérios: o critério de autovalores (eigenvalues) maiores que 1,0, no qual "apenas os fatores que têm raízes latentes ou autovalores maiores que 1 são considerados significantes" (Hair et al., 2009, p. 114); e o critério da porcentagem de variância explicada, que considera, nas 
ciências sociais, que uma solução de fatores que explique $60 \%$ da variância total é satisfatória (Hair et al., 2009). A partir desses critérios, a análise fatorial resultou em quatro fatores, os quais explicam $65,92 \%$ da variância, sendo que o primeiro fator concentra $43,26 \%$ da variância total.

Para avaliar a consistência interna dos fatores, de modo a averiguar se os fatores obtidos na análise são confiáveis, foi realizado o cálculo do Alpha de Cronbach. De acordo com Hair et al. (2009, p. 100), o Alpha de Cronbach é uma "medida de confiabilidade que varia de 0 a 1, sendo os valores de 0,6 a 0,7 considerados o limite inferior da aceitabilidade". O Alpha de Cronbach do fator 1 foi de 0,893; do fator 2 foi 0,886; do fator 3 foi 0,807; enquanto o fator 4 teve um Alpha de 0,846. Logo, todos fatores tem consistência interna e são confiáveis, sendo que o fator 1 apresentou o maior valor de confiabilidade, e o fator 3 apresentou o menor valor, dentre os quatro.

Considerando a amostra pesquisada, os resultados da análise fatorial indicaram a presença de quatro fatores, mantendo-se o mesmo número do modelo original desenvolvido por Fitzgerald et al. (1999), totalizando 22 variáveis com cargas fatoriais superiores a 0,4. Esse é um resultado satisfatório para interpretação da estrutura, conforme apontam Hair et al. (2009).

Apesar de manter os quatro fatores originais, a composição desses se mostrou diferente, como pode ser observado na tabela 3. O fator 1 - Atenção Sexual Indesejada - manteve 4 variáveis em comum com o modelo original, mas engloba três variáveis que originalmente compunham outros fatores. Acredita-se que o variável B ("Recebeu assovios, ligações, chamados impróprios"), originalmente no fator Hostilidade Sexual, demonstra coerência com o sentido do fator Atenção Sexual Indesejada, razão pela qual sofreu essa mudança. Da mesma forma, as variáveis S e P, originalmente no fator Coerção Sexual, também podem ser associadas a comportamentos indesejados/agressões sexuais, típicos da dimensão Atenção Sexual Indesejada. $\mathrm{O}$ fator 2 - Hostilidade Sexista - manteve 3 variáveis em comum com o modelo, mas engloba 2 novas que pertenciam ao fator Hostilidade Sexual, originalmente: variáveis L e F. Esses dois fatores são passíveis de associação de conteúdo, pois ambos se referem ao assédio de gênero, razão pela qual foi observada a mudança.

O fator 3 - Coerção Sexual - manteve três variáveis em comum com o modelo original, mas recebeu outras duas que originalmente pertenciam ao fator Atenção Sexual Indesejada: as variáveis X e V. Isto se deu porque também podem estar relacionadas ao sentido do fator Coerção Sexual, uma vez estão associadas a demandas explícitas por relações sexuais. Da mesma maneira, o fator 4 - Hostilidade Sexual - apresentou o mesmo resultado do modelo original para três variáveis, mas duas variáveis eram originalmente pertencentes à Hostilidade Sexista: H e D. Conforme já mencionado anteriormente, esses dois fatores podem ser facilmente associados, pois ambos se referem ao assédio de gênero.

A Tabela 3 fornece informações sobre a média e desvio-padrão de cada variável em seu fator correspondente, bem como o fator ao qual pertencia no estudo original. 
Tabela 3 - Média e desvio-padrão das variáveis em seus fatores correspondentes.

\begin{tabular}{|c|c|c|c|}
\hline Variáveis & $\overline{\boldsymbol{x}}$ & Dp & Fator \\
\hline \multicolumn{4}{|l|}{ FATOR 1 - Atenção Sexual Indesejada } \\
\hline Sofreu tentativas indesejadas de carícia/afagos/beijos. & 1,20 & 0,631 & ASI \\
\hline Foi tocado, de modo que gerou desconforto. & 1,25 & 0,686 & ASI \\
\hline Passou por tentativas indesejadas de relacionamento sexual/romântico. & 1,26 & 0,701 & ASI \\
\hline Recebeu convites insistentes para encontros, mesmo dizendo "não". & 1,19 & 0,603 & ASI \\
\hline Foi mal tratado por se recusar a fazer sexo. & 1,07 & 0,391 & CS \\
\hline Recebeu assovios, ligações, chamados impróprios. & 1,29 & 0,727 & HSexu \\
\hline Sofreu ameaça de retaliação por recusa a cooperar sexualmente. & 1,09 & 0,429 & CS \\
\hline TOTAL FATOR & 1,19 & 0,469 & \\
\hline \multicolumn{4}{|l|}{ FATOR 2 - Hostilidade Sexista } \\
\hline Teve tratamento diferente pelo sexo (foi menosprezado, mal tratado, etc). & 1,61 & 1,072 & HSexist \\
\hline Ouviu comentários sexistas ofensivos. & 1,46 & 0,916 & HSexist \\
\hline Já foi deprimida (o) por conta do sexo. & 1,26 & 0,737 & HSexist \\
\hline $\begin{array}{l}\mathrm{L} \\
\text { Sofreu olhares constrangedores que geraram desconforto. }\end{array}$ & 1,44 & 0,869 & HSexu \\
\hline $\begin{array}{ll}\text { F } & \text { Ouviu comentários ofensivos sobre sua aparência/atividades sexuais. }\end{array}$ & 1,28 & 0,761 & HSexu \\
\hline TOTAL FATOR & 1,41 & $\mathbf{0 , 7 2 3}$ & \\
\hline \multicolumn{4}{|l|}{ FATOR 3 - Coerção Sexual } \\
\hline T Teve sugestões de promoções mais rápidas em caso de cooperação sexual. & 1,03 & 0,240 & CS \\
\hline U Sofreu temor de ser maltratado em caso de não cooperação sexual. & 1,04 & 0,277 & CS \\
\hline $\begin{array}{ll}\mathrm{X} & \text { Passou por situação de sexo sem consentimento. }\end{array}$ & 1,00 & 0,062 & ASI \\
\hline $\mathrm{V} \quad$ Sofreu tentativa de fazer sexo, sem sucesso. & 1,03 & 0,271 & ASI \\
\hline $\mathrm{O} \quad$ Foi subornado para se envolver sexualmente. & 1,08 & 0,373 & CS \\
\hline TOTAL FATOR & 1,04 & 0,192 & \\
\hline \multicolumn{4}{|l|}{ FATOR 4 - Hostilidade Sexual } \\
\hline H Presenciou exibição/uso de materiais sexistas sugestivos (como pornografia). & 1,19 & 0,602 & HSexist \\
\hline C Passou por tentativas indesejadas de discussão sobre questões sexuais. & 1,35 & 0,776 & HSexu \\
\hline G $\quad$ Observou gestou sexuais ofensivos para si. & 1,31 & 0,732 & HSexu \\
\hline A Ouviu histórias sexuais ofensivas. & 1,62 & 0,969 & HSexu \\
\hline D Ouviu comentários sexuais grosseiros. & 1,44 & 0,891 & HSexist \\
\hline TOTAL FATOR & 1,38 & 0,628 & \\
\hline
\end{tabular}

$\bar{x}=$ =édia; Dp=Desvio-padrão; Fator original=Fator ao qual a variável pertence no estudo original de Fitzgerald et al. (1999); ASI=Atenção Sexual Indesejada; HSexist=Hostilidade Sexista; CS=Coerção Sexual; HSexu=Hostilidade Sexual. Fonte: Dados da pesquisa (2020).

Tendo sido avaliada a análise fatorial, procedeu-se a análise das médias e desvios-padrão para as variáveis e também para os quatro fatores de modo geral, atendendo as variantes da escala de (1) nunca a (5) sempre, a qual se refere à frequência que os servidores vivenciam a situação de assédio sexual. Os resultados da Tabela 3 mostram que as médias gerais dos fatores variaram entre 1,04 e 1,41. Já os desvios-padrão estiveram entre 0,192 e 0,723, onde duas dimensões apresentaram valores considerados baixos, dispersando-se muito pouco da média. Mesmo os valores mais altos de desvio-padrão (0,628 e 0,723) ainda não representam uma dispersão expressiva. A dimensão Coerção Sexual foi o que obteve menor média $(\bar{x}=1,04)$ e desvio-padrão (0,192), indicando conformidade entre as respostas dos participantes da pesquisa. Já o fator 2 - Hostilidade 
Sexista - destacou-se como o de maior média $(\bar{x}=1,41)$ e desvio-padrão $(0,723)$, indicando que, nas variáveis deste fator, a conformidade de respostas foi a menor dentre as quatro dimensões. Todavia, o maior valor de média permite inferir que deste fator que são provenientes as situações mais recorrentes entre os servidores da Instituição.

A partir da Tabela 3, realizou-se uma análise individual dos fatores e suas variáveis. As variáveis relacionadas à dimensão Atenção Sexual Indesejada apresentaram médias entre 1,07 e 1,29. Nesse sentido, mesmo a maior média apresenta valores relativamente baixos. A partir desse dado, pode-se observar que a maior parte das respostas com relação à dimensão estudada envolvem a opção "1 - Nunca" ou "2 - Uma vez". A questão de maior média foi a "B - Recebeu assovios, ligações, chamados impróprios" ( $\bar{x}=1,29)$, demonstrando que, dentre as questões que compõem o fator Atenção Sexual Indesejada, essa foi a que representou uma maior ocorrência entre os servidores da amostra pesquisada, ainda que de forma pouco expressiva. Percebe-se que os valores das médias obtidas nas questões são considerados baixos, com valores de desvio-padrão moderado, indicando que há leve disparidade nas respostas dos servidores.

De maneira geral, a dimensão Hostilidade sexista apresentou baixas médias, oscilando entre os valores 1,26 e 1,61. Esse dado demonstra que, para as questões da dimensão estudada, houve baixa ocorrência de situações que configuram assédio de gênero. Mesmo apresentando médias gerais baixas, há casos representativos de servidores que acabaram passando pelas situações mencionadas na dimensão. A maior média foi percebida para a questão "E - Teve tratamento diferente pelo sexo (foi menosprezado, mal tratado, etc)" ( $\bar{x}=1,61)$. Logo, dentre as questões dessa dimensão, essa foi a situação pela qual os respondentes mais passaram durante seu tempo de serviço na Universidade. O desvio-padrão de 1,072 indica grande dispersão entre as respostas. Apesar da média ser relativamente baixa, esses dados são preocupantes para uma instituição como a pesquisada, de modo que essa situação pode ser considerado um dado grave, demonstrando que o assédio de gênero ainda está fortemente presente entre os servidores da Universidade.

Ao analisar os dados da tabela, nota-se que a dimensão Coerção sexual apresentou as menores médias dentre as quatro dimensões estudadas, oscilando entre os valores 1,00 e 1,08. Esse dado mostra que, para as questões da dimensão estudada, houve baixa ocorrência de situações que configuram coerção sexual. A análise geral também demonstra baixos valores de desvios-padrão, indicando maior conformidade (baixa dispersão) sobre as respostas.

A menor média foi observada para a questão "X - Passou por situação de sexo sem consentimento" ( $\bar{x}=1,00)$, que é a questão de maior gravidade de todo o questionário, visto que, além do assédio sexual, caracteriza ocorrência de violência sexual, assim como a questão "V - Sofreu tentativa de fazer sexo, sem sucesso", já que não há consentimento da vítima na relação sexual. É o que pode ser observado no Art. $7^{\circ}$, inciso III, da Lei nº 11.340/2006, que caracteriza a violência sexual como

[...]qualquer conduta que a constranja a presenciar, a manter ou a participar de relação sexual não desejada, mediante intimidação, ameaça, coação ou uso da força; que a induza a comercializar ou a utilizar, de qualquer modo, a sua sexualidade, que a impeça de usar qualquer método contraceptivo ou que a force ao matrimônio, à gravidez, ao aborto ou à prostituição, mediante coação, chantagem, suborno ou manipulação; ou que limite ou anule o exercício de seus direitos sexuais e reprodutivos (Brasil, 2006, s.p.)

Apesar da média 1,00, há de ser considerado que o desvio padrão foi 0,062 , de modo que nem todos respondentes afirmaram nunca ter passado por essa situação. Ao analisar a distribuição de frequências, percebe-se que $0,4 \%(\mathrm{~N}=2)$ dos respondentes passaram por essa situação por parte de algum colega de trabalho. Essa situação é extremamente grave, visto que são duas pessoas que foram forçadas a manter relação sexual sem consentimento por parte de algum colega de Instituição.

O maior valor médio da dimensão Coerção Sexual foi obtido para a questão "O - Foi subornado para se envolver sexualmente" $(\bar{x}=1,08)$. A grande maioria dos respondentes informou nunca que ter sido subornado para se envolver 
sexualmente. Ainda assim, tem de ser considerado que o problema está atingindo alguns servidores. Diante da análise da dimensão Coerção sexual, apesar das baixas médias e valores de desvio-padrão (indicando baixa dispersão nas respostas), há a ocorrência de graves situações configurando coerção sexual entre os servidores da Universidade. Alguns dados são alarmantes e mostram que tal situação é inadmissível perante uma Instituição como essa.

Ao analisar as variáveis da dimensão Hostilidade Sexual, percebe-se que apresentaram médias entre 1,19 e 1,62. Nesse sentido, mesmo a maior média apresenta valores relativamente baixos. A partir desse dado, pode-se observar que a maior parte das respostas com relação à dimensão estudada envolvem a opção "1 - Nunca" ou "2 - Uma vez". A maior média observada foi da questão "A - Ouviu histórias sexuais ou piadas ofensivas" $(\bar{x}=1,62)$, com desvio-padrão relativamente alto $(0,969)$, demonstrando dispersão nas respostas. Já a menor média refere-se à questão "H - Presenciou exibição/uso de materiais sexistas sugestivos (como pornografia)" $(\bar{x}=1,19)$, com desvio-padrão de 0,602 que indica média dispersão nas respostas.

Dado o exposto sobre as médias e outros dados referentes à dimensão Hostilidade sexista, pode-se dizer que esta apresentou baixas médias para as questões, e desvio-padrão ligeiramente alto, demonstrando certa dispersão nas respostas dos servidores. Ou seja, mesmo apresentando médias gerais baixas, há casos representativos de servidores que acabaram passando pelas situações mencionadas na dimensão.

\subsection{Experiências de Assédio Sexual de acordo com o Sexo}

A fim de identificar se, na instituição pesquisada, mulheres apresentam maiores médias nos casos que configuram algum tipo de assédio, buscou-se separar as médias e desvios-padrão para as respostas das pessoas que afirmaram ser do sexo feminino e masculino, a partir do "Teste T de amostras independentes". Foram calculadas as médias e desvio por variável e também por dimensão estudada. Como somente três respondentes optaram por não responder a qual sexo pertenciam, estas foram desconsideradas nesse momento da análise. Os resultados podem ser visualizados na Tabela 4. 
Tabela 4 - Médias e desvio-padrão sobre experiências de assédio sexual de acordo com o sexo dos respondentes.

\begin{tabular}{|c|c|c|c|c|c|}
\hline \multicolumn{2}{|r|}{ Variáveis por fator } & \multicolumn{2}{|c|}{ Mulheres } & \multicolumn{2}{|c|}{ Homens } \\
\hline & & $\overline{\boldsymbol{x}}$ & Dp & $\overline{\bar{x}}$ & Dp \\
\hline \multicolumn{6}{|c|}{ FATOR 1 - Atenção Sexual Indesejada } \\
\hline $\mathrm{R}$ & Sofreu tentativas indesejadas de carícia/afagos/beijos. & 1,26 & 0,699 & 1,12 & 0,524 \\
\hline Q & Foi tocado, de modo que gerou desconforto. & 1,33 & 0,761 & 1,16 & 0,568 \\
\hline $\mathrm{J}$ & Passou por tentativas indesejadas de relacionamento sexual/romântico. & 1,3 & 0,744 & 1,22 & 0,643 \\
\hline $\mathrm{N}$ & Recebeu convites insistentes para encontros, mesmo dizendo "não". & 1,21 & 0,615 & 1,16 & 0,591 \\
\hline $\mathrm{S}$ & Foi mal tratado por se recusar a fazer sexo. & 1,06 & 0,355 & 1,09 & 0,436 \\
\hline $\mathrm{B}$ & Recebeu assovios, ligações, chamados impróprios. & 1,38 & 0,823 & 1,17 & 0,565 \\
\hline $\mathrm{P}$ & Sofreu ameaça de retaliação por recusa a cooperar sexualmente. & 1,1 & 0,446 & 1,06 & 0,409 \\
\hline TO & TAL FATOR 1 & 1,24 & 0,492 & 1,14 & 0,437 \\
\hline \multicolumn{6}{|c|}{ FATOR 2 - Hostilidade Sexista } \\
\hline $\mathrm{E}$ & Teve tratamento diferente pelo sexo (foi menosprezado, mal tratado, etc). & 1,93 & 1,214 & 1,19 & 0,660 \\
\hline I & Ouviu comentários sexistas ofensivos. & 1,67 & 1,05 & 1,18 & 0,613 \\
\hline $\mathrm{K}$ & Já foi deprimida (o) por conta do sexo. & 1,41 & 0,892 & 1,06 & 0,398 \\
\hline $\mathrm{L}$ & Sofreu olhares constrangedores que geraram desconforto. & 1,61 & 0,976 & 1,23 & 0,657 \\
\hline $\mathrm{F}$ & Ouviu comentários ofensivos sobre sua aparência/atividades sexuais. & 1,35 & 0,852 & 1,2 & 0,622 \\
\hline TO & TAL FATOR 2 & 1,60 & $\mathbf{0 , 8 2 6}$ & 1,17 & 0,475 \\
\hline \multicolumn{6}{|c|}{ FATOR 3 - Coerção Sexual } \\
\hline $\mathrm{T}$ & $\begin{array}{l}\text { Teve sugestões de promoções mais rápidas em caso de cooperação } \\
\text { sexual. }\end{array}$ & $\mathbf{1 , 0 3}$ & 0,234 & 1,03 & 0,250 \\
\hline $\mathrm{U}$ & Sofreu temor de ser maltratado em caso de não cooperação sexual. & 1,06 & 0,340 & 1,02 & 0,163 \\
\hline $\mathrm{X}$ & Passou por situação de sexo sem consentimento. & 1,01 & 0,083 & 1,00 & 0,000 \\
\hline $\mathrm{V}$ & Sofreu tentativa de fazer sexo, sem sucesso. & 1,02 & 0,155 & $\mathbf{1 , 0 5}$ & 0,370 \\
\hline $\mathrm{O}$ & Foi subornado para se envolver sexualmente. & 1,09 & 0,382 & 1,08 & 0,366 \\
\hline \multicolumn{2}{|c|}{ TOTAL FATOR 3} & 1,04 & $\mathbf{0 , 2 0}$ & 1,03 & 0,184 \\
\hline \multicolumn{6}{|c|}{ FATOR 4 - Hostilidade Sexual } \\
\hline $\mathrm{H}$ & $\begin{array}{l}\text { Presenciou exibição/uso de materiais sexistas sugestivos (como } \\
\text { pornografia). }\end{array}$ & 1,21 & 0,630 & 1,17 & 0,568 \\
\hline $\mathrm{C}$ & Passou por tentativas indesejadas de discussão sobre questões sexuais. & 1,42 & 0,836 & 1,26 & 0,689 \\
\hline G & Observou gestou sexuais ofensivos para si. & 1,41 & 0,818 & 1,2 & 0,590 \\
\hline $\mathrm{A}$ & Ouviu histórias sexuais ofensivas. & 1,77 & 1,062 & 1,43 & 0,801 \\
\hline $\mathrm{D}$ & Ouviu comentários sexuais grosseiros. & 1,5 & 0,931 & 1,38 & 0,840 \\
\hline \multicolumn{2}{|c|}{ TOTAL FATOR 4} & 1,46 & 0,699 & 1,29 & 0,512 \\
\hline
\end{tabular}

$\bar{x}=$ Média; Dp=Desvio-padrão; Fonte: Dados da pesquisa (2020).

Analisando as variáveis isoladamente, percebe-se que, em 21 das 23 questões, embora com sutis diferenças, a média obtida para as respondentes do sexo feminino se mostrou superior à média dos homens, confirmando a teoria de Diniz (2014) de que as mulheres, geralmente, são as maiores vítimas de assédio sexual de modo geral. As únicas questões em que os homens apresentaram maior média foram "S - Foi mal tratado por se recusar a fazer sexo" ( $\overline{\mathrm{x}}=1,09)$, e "V - Sofreu tentativa de fazer sexo, sem sucesso" $(\overline{\mathrm{x}}=1,05)$. 
A questão com maior média entre as respondentes mulheres foi " $\mathrm{E}$ - Teve tratamento diferente pelo sexo" $(\overline{\mathrm{x}}=1,93)$, demonstrando o forte recorte de assédio de gênero, sendo essa a situação mais vivenciada pelas respondentes. O desvio-padrão ligeiramente alto $(\mathrm{Dp}=1,214)$ permite inferir que houve dispersão e afastamento das respostas em relação à média. Já a questão de menor média entre as mulheres foi " $X$ - Passou por situação de sexo sem consentimento" ( $\overline{\mathrm{X}}=1,01)$, o que é justificável, uma vez que essa é a situação mais grave apresentada no questionário. A partir dos dados, é possível inferir que as duas pessoas que afirmaram ter passado por situação de sexo sem consentimento foram mulheres, uma vez que para a questão "X" as respostas masculinas obtiveram média 1,00 e desvio-padrão 0,000, indicando conformidade dos homens nas respostas em torno da média.

A questão de maior média para os respondentes homens foi "A - Ouviu histórias sexuais ou piadas ofensivas" ( $\overline{\mathrm{x}}=1,43)$, com desvio-padrão 0,801 , indicando certa conformidade entre as respostas, sendo essa a situação mais vivenciada pelos respondentes homens. A menor média foi observada para a questão "X", conforme já mencionado.

Os dados da tabela 4 reforçam que a maior ocorrência dos casos de assédio sexual se dá entre mulheres. Ainda assim, há de ser considerado que os dados mostram que os homens também têm vivenciado situações de assédio dentro da instituição, sendo que a única questão que nunca foi vivenciada por nenhum homem foi " $\mathrm{X}$ - Passou por sexo sem consentimento" $(\overline{\mathrm{x}}=1,00, \mathrm{Dp}=0,000)$.

Ao realizar o teste $\mathrm{T}$ com a finalidade de identificar se as experiências de assédio sexual diferem entre homens e mulheres, de modo geral, foram obtidas diferenças significativas (Sig. $<0,05$ ) para três das quatro dimensões estudadas: atenção sexual indesejada, hostilidade sexista e hostilidade sexual, conforme demonstrado na Tabela 5.

Tabela 5 - Teste T de diferença de médias quanto ao sexo dos respondentes.

\begin{tabular}{ccc}
\hline Dimensão & Teste T & Sig \\
\hline 1 - Atenção Sexual Indesejada & 2,349 & 0,019 \\
\hline 2 - Hostilidade Sexista & 6,79 & 0,000 \\
\hline 3 - Coerção Sexual & 0,409 & 0,682 \\
\hline 4 - Hostilidade Sexual & 3,112 & 0,002 \\
\hline
\end{tabular}

Fonte: Dados da pesquisa (2020).

A partir dos resultados do teste $\mathrm{T}$, pode-se afirmar, com 95\% de confiança, que as servidoras do sexo feminino apresentaram maiores médias para as dimensões Atenção Sexual Indesejada $(1,24)$, Hostilidade Sexista $(1,60)$ e Hostilidade Sexual $(1,46)$, se comparadas aos servidores do sexo masculino, que apresentaram médias 1,$14 ; 1,17$; e $1,29^{4}$, para as respectivas dimensões.

Como os dados das tabelas revelam, hostilidade sexista e hostilidade sexual foram as formas mais comuns de assédio experimentadas pelos servidores da instituição, tanto homens quanto mulheres. As médias foram ainda maiores para mulheres pois as duas dimensões se referem ao assédio de gênero. Em terceiro lugar, estão as experiências de atenção sexual indesejada. Já as experiências de coerção sexual foram as menos frequentes entre os respondentes. Tais dados vão ao encontro dos resultados obtidos por Fitzgerald et al. (1999), que, em sua pesquisa voltada a servidores militares, também perceberam maiores incidências para os mesmos fatores. Isso demonstra que a incidência e ocorrência de casos de assédio sexual se comporta de modo semelhante nas duas amostras estudadas: de servidores militares e civis.

\footnotetext{
${ }^{4}$ Médias detalhadas na Tabela 4.
} 


\section{Considerações Finais}

Este artigo teve por objetivo analisar a incidência de situações que configuram assédio sexual entre servidores de uma Universidade Federal do Interior do Rio Grande do Sul, a partir do Modelo de Avaliação de Experiências Sexuais proposto por Fitzgerald et al. (1999). De modo mais específico, buscou-se analisar as diferenças nas experiências de assédio sexual de acordo com o sexo dos respondentes.

Obteve-se a participação de 513 servidores da instituição na pesquisa, sendo que a maioria foi representada por mulheres (55,9\%), com idade até 43 anos e que se autodeclaram brancos (89,7\%). Mais de $70 \%$ dos respondentes têm mais altos graus de formação (titulação de Mestrado ou Doutorado), e mais da metade trabalham há no máximo 10 anos na instituição. Quanto à categoria de atuação dos respondentes, foi registrada participação semelhante de servidores docentes e técnicos-administrativos. Destaca-se que a grande maioria (73\%) não ocupava nenhum cargo de chefia no momento da pesquisa.

De acordo com as respostas dos servidores quanto às situações apresentadas, e analisando os dados em conjunto, percebe-se que, para essa escala utilizada, quanto mais próximas de 5 estivessem concentradas as médias, maior seria a gravidade da ocorrência de assédio sexual dentro da instituição. Assim, de modo geral, os resultados afastados de 5 permitem inferir que o ambiente não apresenta grande gravidade sobre o assédio sexual.

Apesar disso, ainda há servidores que indicam terem vivenciado algumas das situações, demonstrando que a violência ainda ocorre na instituição e que o ambiente está longe de ser o ideal, livre de assédio. Ademais, há de ser considerado um dado alarmante: duas pessoas da amostra já passaram por situação de sexo sem consentimento, e nove pessoas já sofreram tentativa de sexo (sem sucesso). Esses dados são extremamente graves para a Instituição estudada. Também foi percebido que, para a amostra pesquisada, as respondentes do sexo feminino são as maiores vítimas de situações que configuram assédio sexual na instituição, uma vez que, das 23 questões apresentadas, em 21 as médias das respondentes mulheres foram superiores às dos homens e, de modo geral, em três das quatro dimensões estudadas, foram percebidas diferenças significativas percebidas através do Teste $\mathrm{T}$ - entre as médias de mulheres e homens, sendo aquelas superiores.

Diante do que foi apresentado, acredita-se que a instituição deve trabalhar firmemente de modo a combater o assédio sexual no seu ambiente de trabalho, e buscar solucionar os casos que ainda estão ocorrendo, por meio do devido tratamento às denúncias e posterior punição aos assediadores. Sabe-se que muitas vítimas ainda se sentem desencorajadas a denunciar, por diversos motivos. Nesse sentido, a Universidade também deve trabalhar no incentivo às denúncias, demonstrando às vítimas sua responsabilidade com um ambiente laboral saudável e livre de assédio.

Dentre as limitações do estudo, destaca-se a baixa produção sobre assédio sexual entre servidores da administração pública federal, o que acaba dificultando a comparação com resultados de outras pesquisas. Desse modo, sugere-se que mais esforços possam ser realizados para conduzir estudos na área da gestão pública. Ademais, percebe-se a escassez de instrumentos quantitativos para aplicação em pesquisas dessa temática, sugerindo-se, assim, novas iniciativas de elaboração de questionários validados que possam mensurar a ocorrência de assédio sexual.

Como sugestões a pesquisas futuras, pode-se utilizar o viés qualitativo, por meio da realização de entrevistas com profissionais da instituição. Além disso, sugere-se que estudos sejam ampliados também com foco no público masculino e, principalmente, que analisem o assédio sexual sob uma perspectiva de gênero e orientação sexual, e não somente sexo (masculino e feminino), englobando a população LGBTQIA ${ }^{5}$.

\footnotetext{
${ }^{5}$ LGBTQIA+ = Lésbicas, gays, bissexuais, transexuais ou transgêneros, queer, intersexo, assexual e outras possibilidades de orientação sexual.
} 


\section{Referências}

Conselho Nacional do Ministério Público [CNMP]. (2016). Assédio Moral e Sexual: previna-se. http://www.mpf.mp.br/sc/arquivos/cartilha-assedio.

Ministério Público do Trabalho [MPT]. (2017). Assédio Sexual no Trabalho: Perguntas e respostas. http://www.mpsp.mp.br/portal/page/portal/cao_cive 1/acoes_afirmativas/inc_social_mulheres/mulh_cartilhas/Cartilha\%20Assedio\%20Sexual\%20-\%20MPT.pdf.

Diniz, M. I. (2014). Mulheres como eu, mulheres como as outras: desvelando o assédio moral e sexual no âmbito do trabalho das comerciárias no Estado do Rio Grande do Norte. Tese de Doutorado em Serviço Social, Universidade do Estado do Rio de Janeiro, RJ, Brasil.

FAHS, A. S. (2016). Movimento Feminista: História no Brasil. https://www.politize.com.br/movimento-feminista-historia-no-brasil/.

Farencena, G. S., Kocourek, S., Silva, A. M., \& Dorion, E. C. H. (2020). Produção sobre assédio sexual no período de 2010 a 2019 : um estudo bibliométrico. Revista Visão: Gestão Organizacional, 9(2), 122-137. https://doi.org/10.33362/visao.v9i2.2415.

Fitzgerald, L. F., Shullman, S. L., Bailey, N., Richards, M., Swecker, J., Gold, Y., \& Ormerod, M., Weitzman, L. (1988). The Incidence and Dimensions of Sexual Harassment in Academia and the Workplace. Journal of Vocational Behavior, 32(2), 152-175. https://doi.org/10.1016/0001-8791(88)90012-7.

Fitzgerald, L. F., Drasgow, F., Magley, V. J., \& Waldo, C. R. (1999). Measuring Sexual Harassment in the Military: The Sexual Experiences Questionnaire (SEQ-DoD). Military Psychology, 11(3), 243-263. 10.1207/s15327876mp1103_3

Fitzgerald, L. F., Gelfand, M. J., \& Drasgow, F. (1995). Measuring Sexual Harassment: Theoretical and Psychometric Advances. Basic and Applied Social Psychology, 17(4), 425-445. https://doi.org/10.1207/s15324834basp1704_2.

Fonseca, J. J. S. (2002). Metodologia da pesquisa científica. Fortaleza: Universidade Estadual do Ceará. Apostila.

Gil, A. C. (2018). Como Elaborar Projetos de Pesquisa (6a ed). Atlas.

Gil, A. C (2008). Métodos e Técnicas de Pesquisa Social (6a ed). Atlas.

Hair, J. F., Black, W. C., Babin, B. J., Anderson, R. E., \& Tatham, R.L. (2009). Análise multivariada de dados (6a ed). Bookman.

Instituto Brasileiro de Geografia e Estatística (2018). Pesquisa Nacional por Amostra de Domicílios Contínua: Diferença do rendimento do trabalho de mulheres e homens nos grupos ocupacionais. https://agenciadenoticias.ibge.gov.br/media/com_mediaibge/arquivos/93fe55e0692c504 efbc849b796921b18.pdf.

Oliveira, T. Z., Guimarães, L. V., \& Ferreira, D. P. (2017). Mulher, Prostituta e Prostituição: da História ao Jardim do Éden. Teoria e Prática em Administração, 7(1), 139-169. http://dx.doi.org/10.21714/2238-104X2017v7i1-33214.

Osterne, M. S. F. (2012). A violência contra a mulher na dimensão cultural da prevalência do masculino. O Público $e$ o Privado, 1(18), 129-145. http://www.seer.uece.br/?journal=opublicoeoprivado\&page=article\&op=view\&path\%5B $\% 5 \mathrm{D}=324$.

Ribeiro, V. A. F. (2018). Estratégias de construção de faces no ciberespaço: assédio sexual em cena. Dissertação de Mestrado em Letras, Universidade Federal de Sergipe, SE, Brasil.

Sá, B. S., Folriani, M. D., \& Rampazo, A. V. (2017). Assédio Sexual: O Poder do Macho na Universidade. Revista Estudos de Administração e Sociedade. 3(2), 22-31. https://doi.org/10.22409/eas.v3i2.70.

Santos, M. A.F. (2018). Trabalho corrompido, dignidade violada: histórias de vida de mulheres assediadas sexualmente em uma organização bancária. Tese de Doutorado em Administração, Universidade de Brasília, DF, Brasil.

Schneider, K. T., \& Swan, S. (1997). Job-Related and Psychological Effects of Sexual Harassment in the Workplace: Empirical Evidence From Two Organizations. Journal of Applied Psychology. 82(3), 401-415. 10.1037/0021-9010.82.3.401.

Teixeira, J. C., \& Rampazo, A. S. V. (2017) Assédio Sexual no contexto acadêmico da administração: o que os lábios não dizem, o coração não sente? Farol Revista de Estudos Organizacionais, 4(11), 1151-1235. https://revistas.face.ufmg.br/index.php/farol/article/view/4586.

Universidade Federal de Santa Maria. UFSM em números. https://portal.ufsm.br/ufsm-em-numeros/publico/index.html.

Vergara, S. C. (2016). Projetos e Relatórios de Pesquisa em Administração (16a ed). Atlas.

Senado Federal. (2011). Cartilha sobre assédio moral e sexual. http://www2.senado.leg.br/bdsf/handle/id/509899.

Ministério da Economia e Do emprego. Comissão para a Igualdade no Trabalho e no Emprego. Governo de Portugal. (2013). Prevenção e combate de situações de assédio no local de trabalho: um instrumento de apoio à autorregulação. http://cite.gov.pt/pt/destaques/compl ementosDestqs/guia_informativo.pdf. 